\title{
4-1BB and CD28 Signaling Plays a Synergistic Role in Redirecting Umbilical Cord Blood T Cells Against B-Cell Malignancies
}

\author{
Syam Tammana, ${ }^{1}$ Xin Huang, ${ }^{2-5}$ Marianna Wong, ${ }^{2-5}$ Michael C. Milone, ${ }^{6,7}$ Linan Ma, Bruce L. Levine, ${ }^{8,7}$ \\ Carl H. June, ${ }^{6,7}$ John E. Wagner, ${ }^{2,3}$ Bruce R. Blazar, $^{2-4}$ and Xianzheng Zhou ${ }^{1-5}$
}

\begin{abstract}
Umbilical cord blood (UCB) T cells can be redirected to kill leukemia and lymphoma cells by engineering with a single-chain chimeric antigen receptor (CAR) and thus may have general applications in adoptive cell therapy. However, the role of costimulatory molecules in UCB T-cell activation and effector functions in context with CAR remains elusive. To investigate the effect of costimulatory molecules (4-1BB and CD28) on UCB T cells, we transduced UCB T cells with lentiviral vectors expressing Green Fluorescent Protein (GFP) and CAR for CD19 containing an intracellular domain of the $\mathrm{CD} 3 \zeta$ chain and either a 4-1BB (UCB-19BB $\zeta$ ) or a CD28 intracellular domain (UCB-1928 $\zeta$ ), both (UCB-1928BB $\zeta$ ), or neither (UCB-19 $\zeta$ ). We found that UCB-19BB $\zeta$ and UCB-28BB $\zeta$ T cells exhibited more cytotoxicity to CD19+ leukemia and lymphoma cell lines than UCB-19 $\zeta$ and UCB-1928 $\zeta$, although differences in secretion of interleukin- 2 and interferon- $\gamma$ by these $\mathrm{T}$ cells were not evident. In vivo adoptive transfer of these T cells into intraperitoneal tumor-bearing mice demonstrated that UCB-19BB $\zeta$ and UCB-1928BB $\zeta$ T cells mounted the most potent antitumor response. The mice adoptively transferred with UCB1928BB $\zeta$ cells survived longer than the mice with UCB-19BB $\zeta$. Moreover, UCB-1928BB $\zeta$ T cells mounted a more robust antitumor response than $\mathrm{UCB}-19 \mathrm{BB} \zeta$ in a systemic tumor model. Our data suggest a synergistic role of 4$1 \mathrm{BB}$ and $\mathrm{CD} 28$ costimulation in engineering antileukemia UCB effector cells and implicate a design for redirected UCB T-cell therapy for refractory leukemia.
\end{abstract}

\section{Introduction}

$\mathbf{T}$ HE ADOPTIVE T-CELl THERAPY approach has demonstrated potential in treating patients with viral infections and cancer (Greenberg and Riddell, 1999; Sadelain et al., 2003; Rossig and Brenner, 2004; Rosenberg et al., 2008). With advances in genetic engineering, in which T cells are engineered with chimeric antigen receptors (CARs) to impart parental monoclonal antibody-directed specificity, the scope of this approach has been extended to treat B-cell malignancies (Sadelain et al., 2003; Rossig and Brenner, 2004). A CAR consists of a single-chain variable fragment of monoclonal antibody fused to CD3 $\zeta$ signaling domain of a T-cell receptor (Eshhar et al., 1993). The choice of the CD19 surface molecule is attractive because of its expression pattern on B-lymphoid progenitors and the lack of expression on progenitor stem cells. CARs designed against CD19 were first introduced by the Sadelain and Cooper groups and showed that peripheral blood T cells were effectively redirected to kill CD19 ${ }^{+}$leukemia cells (Brentjens et al., 2003; Cooper et al., 2003). However, $\mathrm{CD} 3 \zeta$ signaling alone is not sufficient to render a durable and complete T-cell response (Finney et al., 1998; Krause et al., 1998).

The need for costimulatory signaling domains with CARs to establish maximal and sustainable T-cell activation has been demonstrated by several groups (Finney et al., 1998, 2004; Krause et al., 1998; Maher et al., 2002; Haynes et al., 2002a,b; Imai et al., 2004; Friedmann-Morvinski et al., 2005; Pule et al., 2005; Altvater et al., 2006; Kowolik et al., 2006; Loskog et al., 2006; Brentjens et al., 2007; Marin et al., 2007; Wang et al., 2007; Carpenito et al., 2009; Milone et al., 2009). It has been thought that CD28 and 4-1BB signaling domains along with CARs

\footnotetext{
${ }^{1}$ Graduate Program in Microbial Engineering, ${ }^{2}$ Division of Pediatric Blood and Marrow Transplantation, ${ }^{3}$ The Masonic Cancer Center, ${ }^{4}$ Center for Immunology, and ${ }^{5}$ Center for Genome Engineering, University of Minnesota, Minneapolis, MN 55455.

${ }^{6}$ Department of Pathology and Laboratory Medicine and ${ }^{7}$ The Abramson Family Cancer Research Institute, University of Pennsylvania, Philadelphia, PA 19104.

${ }^{8}$ Biostatistics and Informatics Core, The Masonic Cancer Center, University of Minnesota, Minneapolis, MN 55455.
} 
in engineered peripheral blood lymphocytes (PBLs) play an important role in antitumor responses. However, their individual importance to generate optimal cell activation is still under debate. The inclusion of the CD28 intracellular costimulatory signaling domain along with $\mathrm{CD} 3 \zeta$ in CAR has enhanced interleukin-2 (IL-2) production and activation of primary $\mathrm{T}$ cells, resistance to $\mathrm{T}$ regulatory cells in vitro, and tumor cell killing in vivo (Sadelain et al., 2003; Rossig and Brenner, 2004). CARs with the 4-1BB signaling domain are not as potent as CARs with the CD28 signaling domain as demonstrated by Finney et al. (2004). In contrast, Marin et al. (2007) have demonstrated that chimeric receptors with the 4-1BB signaling domain is as efficient as the CD28 signaling domain in terms of short-term cytotoxic activity of CD19 CAR-modified cytokine-induced killer (CIK) cells and interferon- $\gamma($ IFN- $\gamma)$ production. Further, chimeric receptors with the 4-1BB signaling domain significantly enhance the antileukemic cytotoxicity of lymphocytes when compared with lymphocytes with receptors lacking 4-1BB (Imai et al., 2004). Finally, CD28 together with 4-1BB signaling is more potent than CD28 alone in terms of cytotoxicity and IFN- $\gamma$ production (Brentjens et al., 2007). Two more recent studies have demonstrated that either CAR with 4-1BB signal domain or CAR with both the 4-1BB and CD28 signaling domains can mediate enhanced T-cell survival and antitumor efficacy in vivo (Carpenito et al., 2009; Milone et al., 2009).

To date, most studies on adoptive T-cell therapy for cancer and the role of costimulatory signaling in CARs have been done with PBL (Sadelain et al., 2003; Rossig and Brenner, 2004). Cooper and colleagues first reported that naive cord blood $\mathrm{T}$ cells can be differentiated into CD19-specific cytolytic effectors (Serrano et al., 2006). We have further demonstrated that after genetic expression of CD19 CAR via the Sleeping Beauty system, both umbilical cord blood (UCB)-derived CD4 and CD8 T cells become cytotoxic effector cells in vitro and mediate tumor regression in vivo, implicating a role in adoptive therapy for UCB $\mathrm{T}$ cells (Huang et al., 2008). The differences in activation kinetics, cytokine profiles, and T-cell maturity between PBL and UCB imply that the costimulatory molecules required for optimal activation of PBL may simply not apply to UCB T cells (Risdon et al., 1995; Barker and Wagner, 2003; Kaminski et al., 2003; Chao et al., 2004). The Cooper study on UCB T cells only investigated CD19 CAR with the CD3 $\zeta$ domain but did not address the costimulatory signaling requirements (Serrano et al., 2006). This work aims to study the roles of 4-1BB and CD28 costimulatory signaling domains in CD19 CAR in generating potent UCB $\mathrm{T}$ cells against B-lineage leukemia and lymphoma.

\section{Materials and Methods}

\section{Cell culture}

K562 (erythroleukemia) were provided by Dr. Ivan Borrello (Johns Hopkins School of Medicine, Baltimore, MD). K562-CD19 cells were generated by stably transfecting K562 cells with human full-length CD19 cDNA (Huang et al., 2008). HBP-null (pre B-ALL), RS4:11 (infant B-ALL), and Raji (B-cell Burkitt's lymphoma) were obtained from the laboratory of Dr. Tucker LeBien (University of Minnesota, Twin Cities, MN). Daudi cells (B-cell Burkitt's lymphoma) were purchased from American Type Culture Collection (ATCC, Manassas, VA). These cell lines were maintained in medium consisting of RPMI 1640, 10\% heat-inactivated $\left(56^{\circ} \mathrm{C}, 30 \mathrm{~min}\right)$ fetal bovine serum (FBS; HyClone, Logan, UT), 1\% nonessential amino acid, $1 \mathrm{mM}$ sodium pyruvate, $2 \mathrm{mM}$ L-glutamine, $50 \mathrm{U} / \mathrm{ml}$ penicillin, and $50 \mu \mathrm{g} / \mathrm{ml}$ streptomycin. K562-CD19 cells were grown in medium supplemented with G418 (0.5 mg/ml; Invitrogen, Carlsbad, CA). 293T/17 cells (ATCC) were grown in Dulbecco's modified Eagle's medium (Invitrogen) supplemented with 10\% FBS, $50 \mathrm{U} / \mathrm{ml}$ penicillin, and $50 \mu \mathrm{g} / \mathrm{ml}$ streptomycin.

\section{Lentivirus preparation and titering}

Lentiviral production in 293T/17 cells has been previously described (Amendola et al., 2005; Huang et al., 2008). Viral titers were determined in $293 \mathrm{~T} / 17$ cells in 12-well plates $\left(1 \times 10^{5}\right.$ cells per well), which ranged from 1 to $10 \times 10^{7}$ transducing units $/ \mathrm{ml}$.

\section{UCB T-cell transduction}

Discarded UCB was obtained from the Duke University Cord Blood Center, St. Louis Blood Center, New York Blood Center, and the American Red Cross in the Twin Cities, with approval from the University of Minnesota Institutional Review Board. After Ficoll-Hypaque (Mediatech Cellgro, Herndon, VA) gradient separation, UCB mononuclear cells (UCBMNCs) were collected and red blood cells were lysed with ammonium chloride solution (StemCell Technologies, Vancouver, Canada) on ice for 5-10 min. UCBMNCs were washed two times with phosphate-buffered saline (PBS; Invitrogen) and resuspended in human T-cell medium consisting of RPMI-1640 (Invitrogen), 10\% FBS, $10 \mathrm{mM}$ HEPES, $2 \mathrm{mM}$ L-glutamine, $50 \mu \mathrm{M} \beta$-mercaptoethanol, $50 \mathrm{U} / \mathrm{ml}$ penicillin, and $50 \mu \mathrm{g} / \mathrm{ml}$ streptomycin. The cells were transferred into 24-well plates and activated using anti-CD3 and antiCD28-conjugated beads (anti-CD3/CD28 beads) for 5 days. After removal of the beads, activated T cells $\left(2 \times 10^{5}\right)$ were mixed with lentivirus [multiplicity of infection $(\mathrm{MOI})=50$ ] in the presence of $8 \mu \mathrm{g} / \mathrm{ml}$ of polybrene in a $5-\mathrm{ml}$ round-bottom tube. The cells were centrifuged at $3000 \mathrm{rpm}(1800 \times g)$ for $3 \mathrm{hr}$ at $32{ }^{\circ} \mathrm{C}$ (or room temperature) and then were cultured in 24 well plates at $37^{\circ} \mathrm{C}$ overnight. After removal of lentivirus by centrifugation at $1200 \mathrm{rpm}(350 \times g)$ for $10 \mathrm{~min}$, the cells were cultured in 24-well plates in fresh human T-cell medium with IL-2 (50 IU/ml; Chiron, Emeryville, CA) and IL-7 (10 ng/ml; National Cancer Institute Biological Resources Branch, Rockville, MD).

Virus-transduced UCB T cells were expanded in 24-well plates using an OKT3 expansion protocol (Riddell and Greenberg, 1990) and sorted for $\mathrm{GFP}^{+}$cells using fluorescenceactivated cell sorting (FACS) Aria (BD Biosciences, San Jose, CA). The sorted cells were further expanded in T25 flasks using OKT3 expansion and cultured in T-cell medium supplemented with IL-2 and IL-7; cells were restimulated similarly every 14 days.

\section{Flow cytometric analysis}

Cyanine (Cy5)-conjugated $\mathrm{F}\left(\mathrm{ab}^{\prime}\right)_{2}$ fragment of goat antimouse $\operatorname{IgG} \mathrm{F}\left(\mathrm{ab}^{\prime}\right)_{2}$ and $\mathrm{F}\left(\mathrm{ab}^{\prime}\right)_{2}$ fragment of ChromPure goat IgG isotype control antibodies were purchased from 
Jackson ImmunoResearch (West Grove, PA). Fluorescein isothiocyanate-, phycoerythrin (PE)-, or Alexa Fluor 647conjugated mouse IgG1, mouse IgG2b isotypes, anti-human perforin, granzyme A, granzyme $\mathrm{B}, \mathrm{CD} 4, \mathrm{CD} 8, \mathrm{CD} 25, \mathrm{CD} 27$, CD28, CD45RA, CD45RO, CD56, CD62L, CD137 (4-1BB), CD154 (CD40L), and CCR7 were purchased from BD Biosciences. Flow cytometric analysis was carried out on a FACS Calibur using CellQuest Pro software (BD Biosciences) and analyzed using FlowJo software (Tree Star, Portland, OR).

\section{Cytotoxicity and cytokine release assays}

T-cell cytotoxicity assays were carried out using a chromium $\left({ }^{51} \mathrm{Cr}\right.$ ) release assay (Huang et al., 2008). Cytokine release assays were performed by coculture of $1 \times 10^{5} \mathrm{~T}$ cells with $5 \times 10^{4}$ target cells per well in duplicate in 96-well flatbottom plates in a final volume of $200 \mu \mathrm{l}$ T-cell media. After $24 \mathrm{hr}$, supernatants were assayed for production of IL-2 and IFN $-\gamma$ using ELISA (R\&D Systems, Minneapolis, MN).

\section{Western blotting}

T cells $\left(2 \times 10^{6}\right)$ were lysed in $200 \mu$ lysis buffer $(1 \times$ PBS, $1 \%$ sodium dodecyl sulfate [SDS], 10\% glycerol). Cell lysate was then removed by centrifugation. Each sample was denatured under reducing condition and electrophoresed by $12 \%$ SDSpolyacrylamide gel electrophoresis. The sample was then transferred to PVDF membrane (Bio-Rad, Hercules, CA) and immunoblotted with mouse anti-human CD3 $\zeta$ antibody (BD Biosciences). The blot was incubated with horseradish peroxidase-conjugated anti-mouse IgG and detected by ECL Western Blotting Analysis System (GE Healthcare, Piscataway, NJ).

\section{In vivo antitumor assays}

Eight- to 10-week-old female NOD/SCID (NOD.CB17$\mathrm{Pkrdc}$ scid $/ \mathrm{J}$, stock number: 001303) mice were purchased from the Jackson Laboratory (Bar Harbor, ME), and all animal work was conducted at the University of Minnesota Animal Facility in accordance with institutional guidelines. On day 6, the mice were $\gamma$-irradiated (2.5 Gy, Cesium-137). On the following day, mice were injected in the peritoneum with $10^{6}$ Daudi-ffluc (Daudi cells transduced with a lentiviral vector encoding firefly luciferase and truncated nerve growth factor receptor [NGFR]) (Huang et al., 2008). On day 3, the mice receiving Daudi-ffluc were examined for tumor engraftment by bioluminescent imaging (BLI). BLI was carried out after injection of sodium pentobarbital and D-luciferin (Xenogen, Hopkinton, MA); images were collected and analyzed using the Xenogen-IVIS Imaging System. A constant region-ofinterest was drawn over the tumor region and the intensity of the signal was measured as total photon flux normalized for exposure time and surface area and expressed in units of photons $/ \mathrm{sec} / \mathrm{cm}^{2} /$ steradian. On day 0 , mice $(n=4$; see Fig. $5 \mathrm{~A}-\mathrm{C})$ were placed into six groups: five groups of mice each received two intraperitoneal (i.p.) infusions of UCB1-19 $\zeta$, UCB1-19BB $\zeta$, UCB1-1928 $\zeta, \mathrm{UCB} 1-1928 B B \zeta$, and UCB1-GFP T cells $\left(5 \times 10^{6} /\right.$ mouse) on days 0 and 4 ; and one group of mice received no T-cell infusion (the tumor only control group). Tumor BLI was performed every 4 days after T-cell infusion. For the animal survival experiment shown in Fig. 5D, tumorbearing mice $(n=7)$ received either UCB1-19BB $\zeta$ or UCB1-
1928BB $\zeta$ infusion, and a third tumor control group received no T-cell infusions. Mice were then monitored for survival without imaging manipulations. For establishing a systemic tumor model (see Fig. 6A and B), Raji-ffluc cells (Raji cells lentivirally transduced with firefly luciferase and NGFR) were intravenously (i.v.) given to NOD/SCID mice after irradiation. Six days after tumor injection, three groups of mice ( $n=7$ per group) received two i.v. infusions of UCB2-19BB $\zeta$, UCB2-1928BB $\zeta$, and UCB2-GFP T cells $\left(10 \times 10^{6}\right.$ per mouse $)$ at 4-day intervals and one group of mice $(n=7)$ received PBS as control. Human IL-2 $\left(2.5 \times 10^{4}\right.$ IU per mouse $)$ i.p. injections were given every 2 days after T-cell infusion for 10 days.

\section{Statistical analyses}

A three-way analysis of variance using factors such as treatment, donor, and effector-to-target $(E: T)$ ratios was used to analyze the data shown in Fig. 3A and B. Mixed linear models were applied to analyze the datasets with repeat measurements of outcome (intensity) as shown in Figs. 5C and $6 \mathrm{C}$. To make the outcome closer to normal distribution, all analyses from mixed models were based on natural logtransformed outcome variables. The number of days after treatment was treated as a discrete variable. Interaction term of treatment and number of days after treatment was included in the model if it was significant. Baseline values of intensity were also adjusted in the models. Covariance matrixes of measurement errors were set as unstructured. $p$-Values from pairwise comparisons were adjusted with the Bonferroni method. Kaplan-Meier log-rank tests were used to analyze Fig. 5D. Statistical analyses were conducted using the SAS 9.1 software (Cary, NC). $p$-Values less than 0.05 were considered statistically significant.

\section{Results}

Lentivirus-mediated coexpression of CD19 CAR and GFP in UCB T cells

The CD19 CAR constructs are shown in Fig. 1A. They constitute a single-chain variable region of an antibody fragment against CD19, a CD $\alpha \alpha$ hinge and transmembrane region, and a $\mathrm{CD} 3 \zeta$ chain's intracellular domain and either a

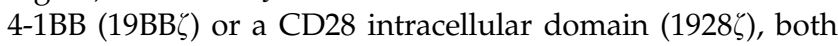

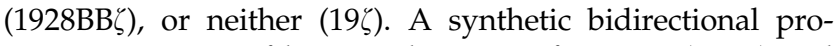
moter consisting of human elongation factor $1 \alpha(\mathrm{EF} 1 \alpha)$ and minimal cytomegalovirus core element (mCMV) was used to regulate CARs and GFP expression, respectively (Amendola et al., 2005).

For effective lentiviral transduction, UCBMNCs from three units (UCB1, UCB2, and UCB3) were activated by CD3/CD28 beads and spin transduced with GFP alone or GFP with 19 $\zeta, 19 B B \zeta, 1928 \zeta$, and $1928 B B \zeta$ CARs. A fourth unit (UCB4) was similarly activated and transduced with GFP or GFP with $19 B B \zeta$ or $1928 B B \zeta$. After transduction, the cells were expanded using OKT3 as described and sorted for GFP (Riddell and Greenberg, 1990). After another round of OKT3 expansion, the sorted cells were analyzed for the expression of both GFP and CARs using a polyclonal antibody directed against variable fragments of CARs.

Figure $2 \mathrm{~A}$ shows that $>90 \%$ of transduced UCB1 T cells expressed GFP. The intensity level of GFP was higher in the cells transduced with GFP alone than the cells transduced 


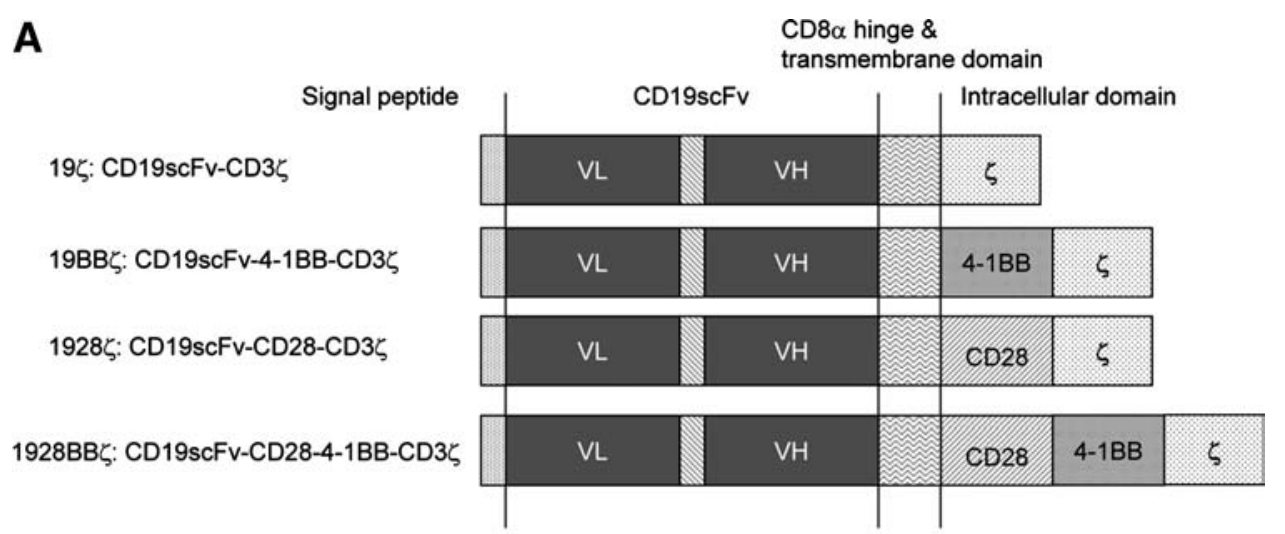

B

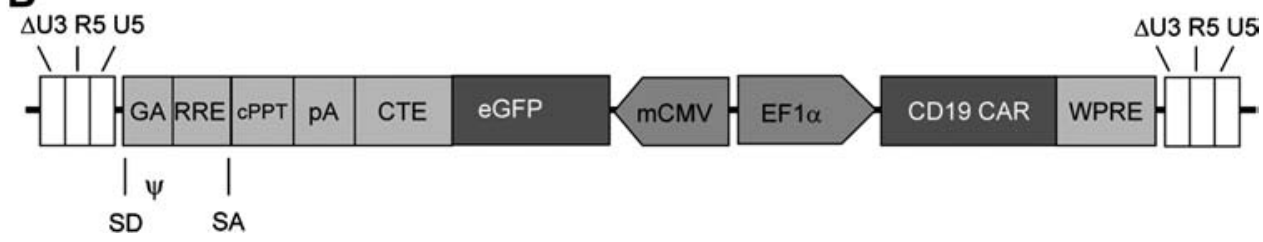

FIG. 1. Schematic representation of the chimeric antigen receptors (CARs) for CD19 and the lentiviral vector used in this study. (A) CD19 CARs: 19 $\zeta, 19 \mathrm{BB} \zeta, 1928 \zeta$, and 1928BB $\zeta$. (B) A lentiviral vector with a bidirectional promoter of human EF1 $\alpha$ and mCMV expressing CD19 CARs $(19 \zeta, 19 \mathrm{BB} \zeta, 1928 \zeta$, and 1928BB $\zeta$ ) and GFP. CARs, chimeric antigen receptors; CMV, human cytomegalovirus; $\mathrm{CPPT}$, central polypurine tract; CTE, constitutive element from the Mason-Pfizer monkey virus; $\mathrm{EFI} \alpha$, elongation factor $1 \alpha$; eGFP, enhanced green fluorescent protein; GA, $5^{\prime}$ portion of the gag gene; mCMV, minimal core promoter element; RRE, Rev-response element; SA, splice acceptor; SD, splice donor; VH, variable domain of heavy chain; VL, variable domain of light chain; WPRE, woodchuck hepatitis virus posttranscriptional regulatory element.

with $19 \zeta, 19 \mathrm{BB} \zeta, 1928 \zeta$, and $1928 \mathrm{BB} \zeta \mathrm{CARs}$ owing to the coding of two proteins by the bidirectional promoter (Amendola et al., 2005). The cell surface expression level of CARs appeared highest in UCB-19BB $\zeta$ T cells, followed by UCB-19 $\zeta$, UCB-1928 $\zeta$, and UCB-1928BB $\zeta$ (Fig. 2A). Similar levels of GFP and CAR expression in UCB2 and UCB3 were also observed (data not shown). Western blotting analysis confirmed the correct sizes of CAR protein expression and the relative higher expression in UCB1-19BB $\zeta$ and UCB1-19 $\zeta$

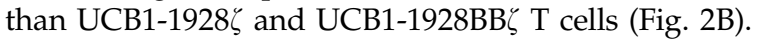

\section{Immunophenotype of engineered UCB T cells expressing CD19 CARs}

The phenotype of bulk UCB T cells transduced with CD19 CARs with costimulatory signaling domains was assessed by flow cytometry on days 13 (UCB1), 10 (UCB2), and 25 (UCB4) after OKT3 expansion. Table 1 shows that UCB1 and UCB4 T-cell cultures contained both $\mathrm{CD}^{+}(14-79 \%$ for UCB1 and $35-73 \%$ for UCB4) and $\mathrm{CD}^{+}$(14-65\% for UCB1 and $33-54 \%$ for UCB4) T cells, whereas UCB2 contained a predominance $(>86 \%)$ of $\mathrm{CD}^{+} \mathrm{T}$ cells. All three UCB T-cell cultures were $\mathrm{CD} 25^{\text {high }}, \mathrm{CD} 27^{\text {low-int }}, \mathrm{CD} 28^{\text {low-int }}, \mathrm{CD} 45 \mathrm{RA} \mathrm{A}^{\text {high }}$, $\mathrm{CD}_{5} \mathrm{RO}^{\text {high }}, \mathrm{CD} 56^{\text {low-high }}, \mathrm{CD} 62^{\text {low }}, \mathrm{CD} 137^{\text {low }}, \mathrm{CD} 154^{\text {low-int }}$, NKG2D ${ }^{\text {low-high }}$, and CCR7 ${ }^{-}$. They were also perforin ${ }^{\text {low }}$ and granzyme $\mathrm{B}^{\text {high }}$ (data not shown). It appears that these $\mathrm{T}$ cells cultured for 2-4 months represent effector memory T-cell phenotypes $\left(\mathrm{CD} 45 \mathrm{RA}^{+} \mathrm{RO}^{+} \mathrm{CD} 25^{+} \mathrm{CCR}^{-} \mathrm{CD} 62 \mathrm{~L}^{\text {low }}\right.$ ) (Sallusto and Lanzavecchia, 2004). However, there appears to be no difference in immunophenotypes between UCB T cells with CAR CD28 signaling (1928)), CAR 4-1BB signaling (19BBל), both CD28 and 4-1BB (1928BB $\zeta)$, and CAR T cells without costimulatory signaling $(19 \zeta)$.

\section{Engineered UCB T cells with 4-1BB or both 4-1BB and CD28 signaling showed enhanced cytotoxicity against $C D 19^{+}$leukemia and lymphoma cells}

To determine the effect of CD19 CARs with different signaling domains on cytolytic activity of transduced UCB T cells, a standard 4-hr chromium release assay was utilized. Figure $3 \mathrm{~A}$ and $\mathrm{B}$ shows that UCB1 and UCB2 T cells expressing CD19 CARs with either 4-1BB (19BBל) or CD28 $(1928 \zeta)$, both $(1928 B B \zeta)$, or neither $(19 \zeta)$ specifically killed $\mathrm{CD}^{+}{ }^{+}$Daudi lymphoma, RS4:11, and HPB-null B-lineage acute lymphoblastic leukemia (B-ALL) cell lines as well as CD19-transfected K562 erythroleukemia cells (K562-CD19). $\mathrm{CD} 19^{-} \mathrm{K} 562$ cells were either not killed or slightly killed at a high E:T ratio (30:1) possibly because of the presence of natural killer (NK) cells in the bulk population. UCB-19BB $\zeta$ and UCB-1928BB $\zeta$ from two donors (UCB1 and UCB2) ap-

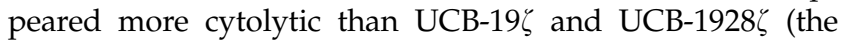
data from $E: T$ ratios of $30: 1$ and $1: 1$ were statistically analyzed; $19 \zeta$ versus $19 \mathrm{BB} \zeta, p \leq 0.0001 ; 19 \zeta$ versus $1928 \zeta, p=0.42$; $19 \zeta$ versus $1928 \mathrm{BB} \zeta, p=0.002 ; 19 \zeta$ versus $\mathrm{GFP}, p \leq 0.0001$; $19 \mathrm{BB} \zeta$ versus $1928 \zeta, p \leq 0.0001 ; 19 \mathrm{BB} \zeta$ versus $1928 \mathrm{BB} \zeta$, $p=0.69 ; 19 \mathrm{BB} \zeta$ versus $\mathrm{GFP}, 1928 \zeta$ versus $1928 \mathrm{BB} \zeta, 1928 \zeta$ versus GFP, and 1928BB $\zeta$ versus GFP, $p \leq 0.0001$; Fig. $3 \mathrm{~A}$ and B), suggesting that 4-1BB signaling may enhance UCB T-cell cytotoxicity as has been shown in PBLs (Imai et al., 2004; Marin et al., 2007). As expected, control UCB T cells transduced with GFP alone (UCB1-GFP and UCB2-GFP) did not lyse either $\mathrm{CD}_{19}{ }^{+}$or $\mathrm{CD} 19^{-}$target cells (Fig. 3A and B; data not shown for UCB3-GFP and UCB4-GFP). These results demonstrate that UCB T cells expressing CARs with 4-1BB or both 4-1BB and CD28 signaling domains displayed enhanced cytotoxicity against $\mathrm{CD} 19^{+}$target cells, indicating 


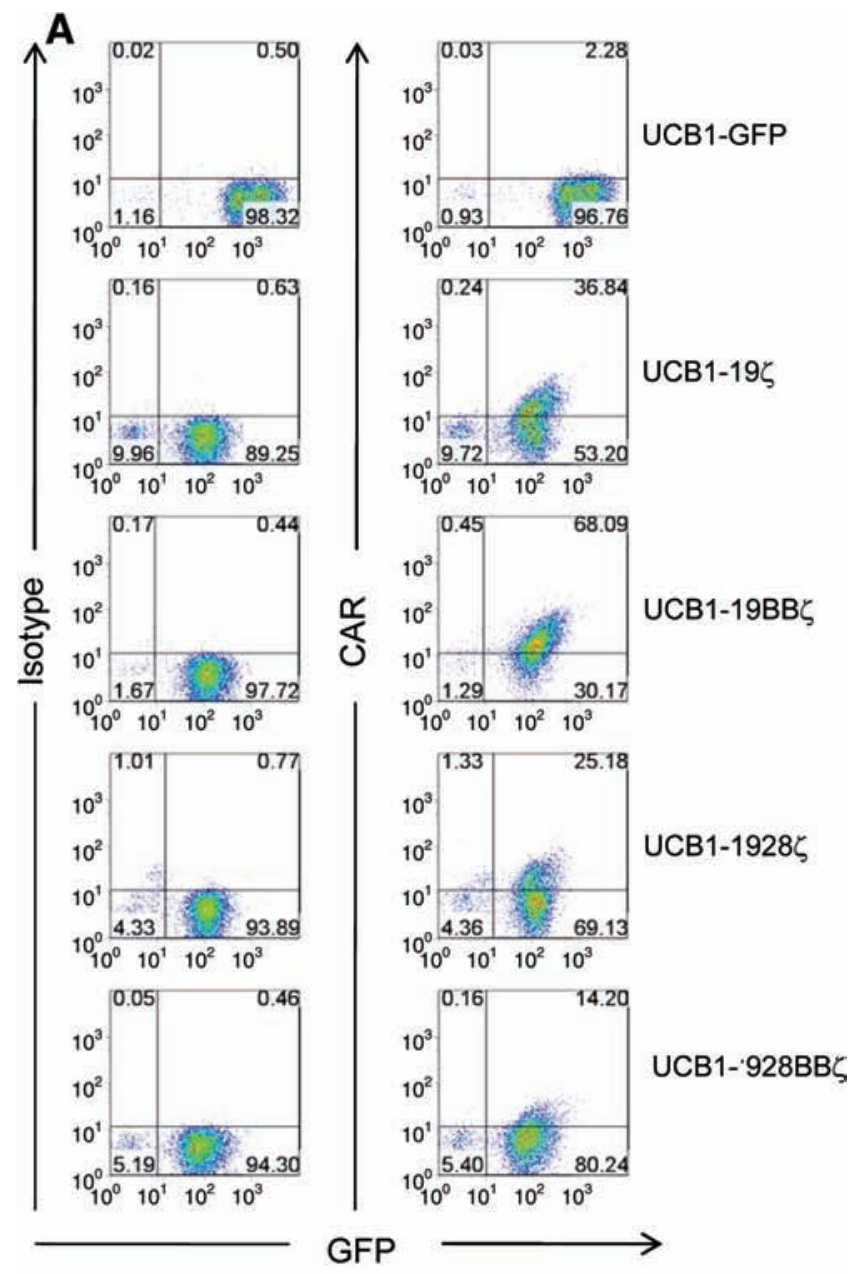

B

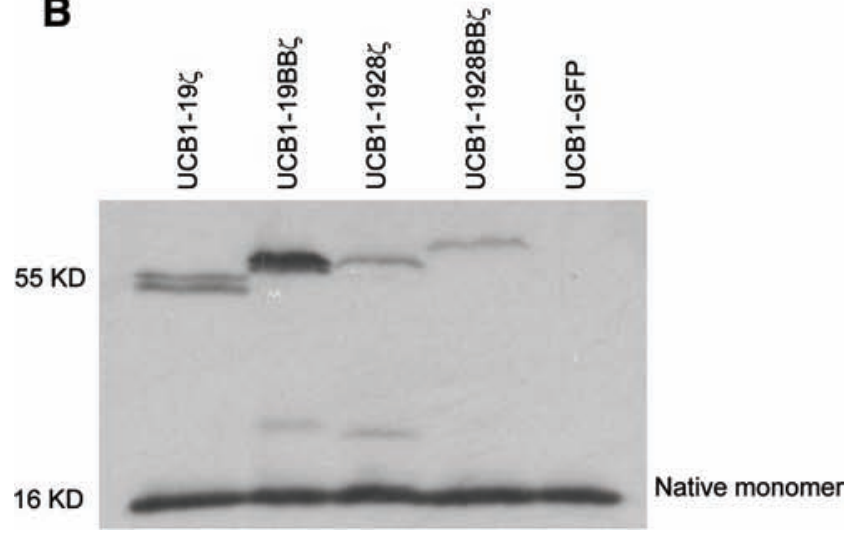

FIG. 2. Cell surface expression of CARs after transduction. (A) Expression of CAR and GFP in UCB1 T cells after transduction and cell sorting for GFP. Cy5-conjugated goat anti-mouse $\mathrm{F}(\mathrm{ab})_{2}$ antibody was used to visualize the surface expression of CD19 CARs. Similar data were obtained for UCB2, UCB3, and UCB4 T cells (not shown). It should be noted that frequent background CAR staining in UCB-GFP cells or untransduced UCB mock cells was observed, but this was not evident in peripheral blood lymphocytes (data not shown) (Huang et al., 2008). (B). Western blotting of CAR expression in transduced UCB T cells. One out of at least five representative data is shown. UCB, umbilical cord blood. Color images available online at www.liebertonline. com/hum. that 4-1BB signaling is more critical than CD28 in UCB T-cell cytotoxicity.

\section{Production of IL-2 and IFN- $\gamma$ by engineered UCB T cells}

The superior cytolytic activity of UCB T cells expressing CD19 CARs with 4-1BB or both 4-1BB and CD28 signaling domains against $\mathrm{CD} 19^{+}$target cell lines prompted us to examine the cytokine secretion profile of these engineered UCB $\mathrm{T}$ cells. We hypothesized that UCB T cells expressing CD19 CAR with 4-1BB or CD28 signaling domain alone or both would increase expression levels of IL-2 and/or IFN- $\gamma$ as has been previously shown that CD28 or 4-1BB enhances IL-2 and/or IFN- $\gamma$ production in PBLs (Sadelain et al., 2003; Rossig and Brenner, 2004). However, UCB T cells derived from three (UCB1, UCB2, and UCB3) out of four donors tested bearing CD19 CARs with $(19 B B \zeta, 1928 \zeta$, and $1928 B B \zeta)$ or without $4-1 \mathrm{BB}$ or CD28 signaling domains (19弓) consistently produced similar amounts of IFN- $\gamma$ in response to CD19 antigen on Daudi and CD19-transfected K562 cells (K562-CD19) but not CD19- K562 cells (Fig. 4A). This is in agreement with a previous report showing that CIK cells retrovirally transduced with CD19 CARs with 4-1BB or CD28 signaling produced a similar level of IFN- $\gamma$ compared with CIK with the same CAR lacking the costimulatory signaling (Marin et al., 2007). We also examined IL-2 production by engineered UCB T cells. Surprisingly, we found that IL-2 levels in the engineered UCB T cells were variable from donor to donor. UCB1 T cells expressing CD19 CAR with or without 4-1BB or CD28 signaling domains produced significant levels of IL-2 when they encountered CD19transfected K562 cells (K562-CD19) but not CD19 ${ }^{+}$Daudi cells (Fig. 4B). These results not only support our previous observation that both UCB and PBL T cells engineered with the Sleeping Beauty transposon encoding CD19 CAR with 4-1BB signaling domain produced IL-2 only in response to K562-CD19 cells (Huang et al., 2008), but also show no superior activity in IL-2 and IFN- $\gamma$ production by CAR UCB T cells with CD28 signaling alone or both CD28 and 4-1BB signaling domains which is in agreement with a recent report using PBLs (Milone et al., 2009). The second (UCB2) and third (UCB3) donor engineered T cells were capable of producing IFN- $\gamma$ and IL-2 to K562-CD19 and Daudi stimulation (data not shown). It is not yet clear why different donor UCB $\mathrm{T}$ cells transduced with CD19 CAR produced variable levels of IL-2 although they consistently produced IFN- $\gamma$. In addition, a thymidine incorporation assay did not reveal any difference for CAR UCB T cells with 4-1BB or CD28 alone or together when they were cocultured with Daudi and K562-CD19 cells (data not shown). Nevertheless, our results demonstrate that inclusion of either 4-1BB or CD28 or both signaling domains into CD19 CARs has an equivalent effect on IFN- $\gamma$ and IL-2 production by engineered UCB T cells.

\section{Engineered 1928BB $\zeta T$ cells can mount more potent antitumor responses in vivo}

Next we evaluated whether there is any cytotoxicity difference among UCB1-derived $19 \zeta, 19 \mathrm{BB} \zeta, 1928 \zeta$, and $1928 \mathrm{BB} \zeta \mathrm{T}$ cells (mixtures of both $\mathrm{CD}^{+}$and $\mathrm{CD} 8^{+}$T-cell subsets; Table 1 ) that could lead to antitumor efficacy against established CD19 ${ }^{+}$ human Daudi lymphoma in NOD/SCID mice. To continuously 
Table 1. Phenotyping of CD19 Chimeric Antigen Receptor Umbilical Cord Blood T Cells

\begin{tabular}{|c|c|c|c|c|c|c|c|c|c|c|c|c|c|}
\hline \multirow[b]{2}{*}{ Marker (\%) } & \multicolumn{5}{|c|}{ UCB1 (day 13) } & \multicolumn{5}{|c|}{ UCB2 (day 10) } & \multicolumn{3}{|c|}{ UCB4 (day 25) } \\
\hline & GFP & $19 \zeta$ & $19 B B \zeta$ & $1928 \zeta$ & $1928 B B \zeta$ & GFP & $19 \zeta$ & $19 B B \zeta$ & $1928 \zeta$ & $1928 B B \zeta$ & GFP & $19 B B \zeta$ & $1928 B B \zeta$ \\
\hline CD4 & 32 & 79 & 14 & 40 & 40 & 88 & 86 & 99 & 90 & 95 & 59 & 73 & 35 \\
\hline CD8 & 65 & 14 & 42 & 60 & 44 & 10 & 24 & 1 & 5 & 2 & 46 & 33 & 54 \\
\hline CD25 & 65 & 89 & 78 & 90 & 84 & 76 & 86 & 98 & 89 & 96 & 35 & 66 & 12 \\
\hline CD27 & 28 & 17 & 40 & 43 & 46 & 8 & 44 & 40 & 42 & 46 & 19 & 36 & 39 \\
\hline CD28 & 6 & 39 & 7 & 21 & 17 & 5 & 19 & 16 & 13 & 11 & 39 & 81 & 12 \\
\hline CD45RA & 83 & 90 & 97 & 95 & 92 & 18 & 66 & 68 & 61 & 66 & 52 & 82 & 90 \\
\hline CD45RO & 50 & 58 & 64 & 59 & 56 & 76 & 87 & 98 & 91 & 96 & 77 & 98 & 87 \\
\hline CD56 & 70 & 32 & 74 & 76 & 66 & 32 & 37 & 66 & 37 & 51 & 3 & 6 & 22 \\
\hline CD62L & 5 & 7 & 5 & 3 & 3 & 5 & 6 & 1 & 2 & 3 & 33 & 24 & 20 \\
\hline CD137 (4-1BB) & 2 & 1 & 5 & 1 & 1 & 1 & 1 & 1 & 2 & 1 & 0 & 1 & 1 \\
\hline CD154 (CD40L) & 10 & 15 & 2 & 15 & 8 & 7 & 58 & 67 & 60 & 55 & 5 & 28 & 17 \\
\hline NKG2D & 70 & 13 & 89 & 64 & 57 & 8 & ND & 2 & 1 & 4 & 43 & 41 & 58 \\
\hline CCR7 & 1 & 1 & 1 & 1 & 1 & 1 & 1 & 1 & 1 & 1 & 0 & 1 & 1 \\
\hline
\end{tabular}

Data not shown for UCB3.

Abbreviations: GFP, Green Fluorescent Protein; ND, not done; UCB, umbilical cord blood.

monitor the tumor burden of Daudi cells by using time dynamic BLI, we genetically engineered the Daudi cells to constitutively express firefly lucieferase enzyme (Daudi-ffluc) (Huang et al., 2008). We injected Daudi-ffluc cells i.p. and allowed them to establish tumor in the mice. Five and 9 days after tumor injection, five groups of mice (four mice per group) were i.p. infused with one of the engineered $19 \zeta, 19 \mathrm{BB} \zeta, 1928 \zeta$, $1928 \mathrm{BB} \zeta$, and GFP T cells. BLI was performed as per schedule shown in Fig. 5A. All the mice in the control group, which did not receive cell-based therapy, showed continued tumor
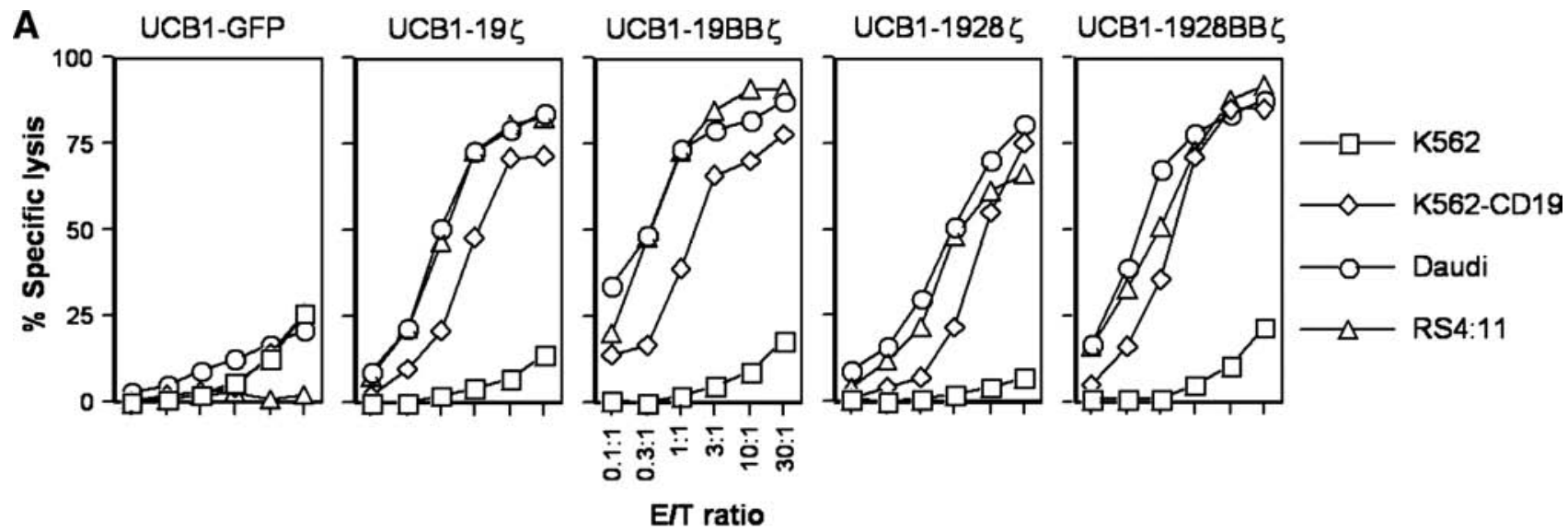

EIT ratio

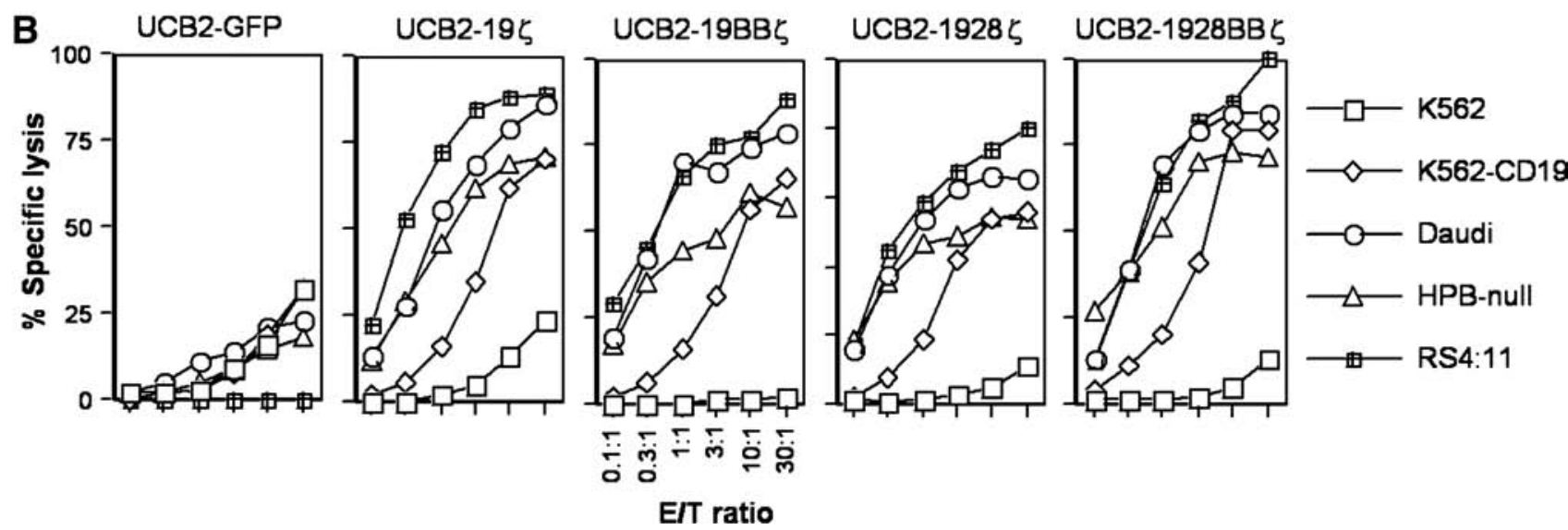

FIG. 3. Engineered T cells specifically kill CD19+ leukemia and lymphoma cells. A 4-hr ${ }^{51} \mathrm{Cr}$-release assay was utilized to assess cytotoxicity of UCB T cells against CD19 ${ }^{+}$target cells. One out of four representative data from UCB1 (A) and UCB2 (B) $\mathrm{T}$ cells is shown. E:T ratio, effector-to-target ratio. 

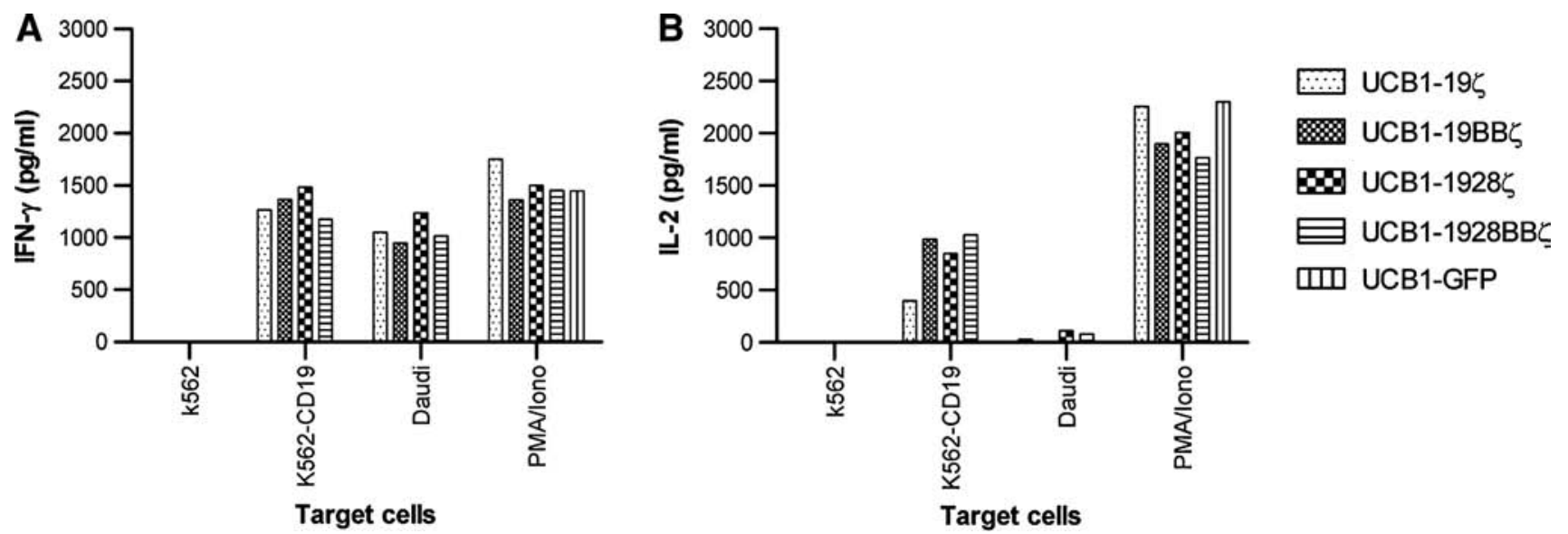

FIG. 4. IL-2 and IFN- $\gamma$ production profile by engineered T cells. (A) IFN- $\gamma$ secretion. (B) IL-2 production. As a positive control, UCB-derived T cells were stimulated in medium with phorbol myristate acetate (PMA) (50 ng/mL) and ionomycin $(1 \mu \mathrm{M})$. Background cytokine production was determined from T cells and tumor cells alone. Both IFN- $\gamma$ and IL-2 assays were conducted simultaneously by ELISA. IL-2 production was also examined by intracellular cytokine staining (BD Biosciences) (data not shown). One out of two representative data is shown. IFN- $\gamma$, interferon- $\gamma$; IL-2, interleukin-2.

growth (Fig. 5B). Similarly, all the mice receiving UCB1-GFP T cells without CD19 CAR experienced continued tumor growth. The mice receiving UCB1-19 $\zeta \mathrm{T}$ cells showed no significant controlled tumor growth when compared with UCB1-GFP ( $p>0.05)$. The mice receiving UCB1-1928 $\zeta \mathrm{T}$ cells also showed no difference in tumor growth control compared with the mice receiving $\mathrm{UCB} 1-19 \zeta(p>0.05)$. The mice receiving $\mathrm{UCB} 1-19 \mathrm{BB} \zeta$ and UCB1-1928BB $\zeta$ displayed significant tumor regression compared with the control groups (control vs. 19BB $\zeta, p=0.0024$; control vs. $1928 \mathrm{BB} \zeta, p<0.0001$; GFP vs. $1928 \mathrm{BB} \zeta, p=0.0004)$ or the mice receiving UCB1-19 $\zeta(19 \zeta$ vs. $1928 \mathrm{BB} \zeta, p=0.025)$ or

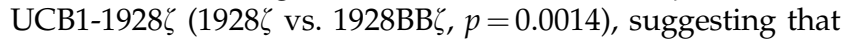
$4-1 B B$ signaling seems more critical than CD28 in redirecting UCB T cells for antitumor responses in vivo (Fig. 5B). Statistical analyses indicated that there was no significant difference in tumor regression between the mice infused with 19BB $\zeta$ and 1928BB $\zeta$ UCB T cells ( $p=0.15$, Fig. 5C). To further test whether UCB1-1928BB $\zeta$ T cells could provide a better survival advantage compared with UCB1-19BB $\zeta$ T cells, an independent survival experiment was conducted without BLI. Figure 5D shows that the mice (five to seven mice per group) infused with 1928BB $\zeta$ T cells survived longer than the mice infused with $19 \mathrm{BB} \zeta \mathrm{T}$ cells (control vs. $19 \mathrm{BB} \zeta, p=1$; control vs. $1928 \mathrm{BB} \zeta, p=0.0015 ; 19 \mathrm{BB} \zeta$ vs. $1928 \mathrm{BB} \zeta, p=0.02$ ), suggesting that $1928 \mathrm{BB} \zeta$ is superior to $19 \mathrm{BB} \zeta$ in UCB T cells concerning animal survival.

To explore the homing ability of engineered UCB T cells expressing 19BB $\zeta$ and 1928BB $\zeta$ CARs, a systemic mouse model was used in which firefly luciferase-transduced Raji cells were i.v. injected into NOD/SCID mice and the tumor was allowed to establish for 5 days in a way similar to the i.p. experiment described in Fig. 5A. Five days later, four groups of mice (seven mice per group) each were given two i.v. infusions of the engineered $19 \mathrm{BB} \zeta, 1928 \mathrm{BB} \zeta$, and GFP UCB2 $\mathrm{T}$ cells (all $>86 \%$ CD4 T-cell subsets; Table 1 ) along with human IL-2. BLI was performed as per the schedule shown in Fig. 6A. All the mice in the control group receiving no cellbased therapy showed continued tumor growth. Similarly, all the mice receiving UCB2-GFP cells experienced continued tumor growth (control vs. GFP on days 2 and $8, p=1$ ). Mice receiving UCB2-1928BB $\zeta$ T cells showed much better control in tumor growth compared with the mice receiving UCB219BB $\zeta$ T cells (Fig. 6B and C). BLI intensity in the mice treated with UCB2-1928BB $\zeta$ T cells was about one third the levels of the mice treated with UCB2-19BB $\zeta$ T cells on day 8 (Fig. 6C; on day 2 , GFP vs. $19 \mathrm{BB} \zeta, p=0.12$; GFP vs. $1928 \mathrm{BB} \zeta, p<0.001$; $19 \mathrm{BB} \zeta$ vs. $1928 \mathrm{BB} \zeta, p=0.70$; on day 8 , GFP vs. $19 \mathrm{BB} \zeta, p<$ 0.001 ; GFP vs. $1928 \mathrm{BB} \zeta, p<0.001 ; 19 \mathrm{BB} \zeta$ vs. $1928 \mathrm{BB} \zeta, p<$ $0.001)$. Altogether, these data demonstrate that both $4-1 \mathrm{BB}$ and CD28 signaling domains play a synergistic role in directing CD19 CAR-engineered UCB T cells against CD19 ${ }^{+}$ tumor cells in vivo.

\section{Discussion}

Several important findings appear in this report regarding the costimulatory signaling requirements in generating CD19 CAR-redirected UCB T cells against $\mathrm{CD} 19^{+}$leukemia and lymphoma cells. First, inclusion of the 4-1BB costimulatory molecule in CD19 CAR seems more critical than CD28. Second, both 4-1BB and CD28 costimulation in CD19 CARengineered UCB T cells acts synergistically and mounts the most potent antitumor responses in vivo in both local and systemic xenogenic tumor models.

In this study, we transduced UCB T cells with lentiviral vectors expressing GFP and CD19 CARs containing an intracellular domain of $\mathrm{CD} 3 \zeta$ chain and either a 4-1BB (19BB $\zeta)$

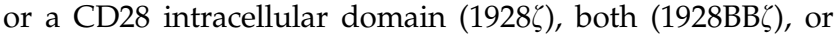

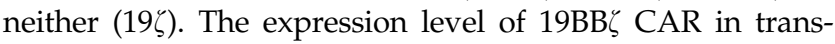
duced UCB T cells appears the highest, followed by $19 \zeta$, $1928 \zeta$, and $1928 \mathrm{BB} \zeta$. The lower expression of $1928 \zeta$ and 1928BB $\zeta$ CARs may have been the result of a dileucine motif that is present in the CD28 intracellular domain. The displacement of the dileucine motif in the CD28 intracellular domain from its natural framework to an artificial context may inadvertently expose it to protein-sorting machinery, thereby limiting the expression of CD28 intracellular domain-bearing CARs (Nguyen et al., 2003). As B-cell 
A
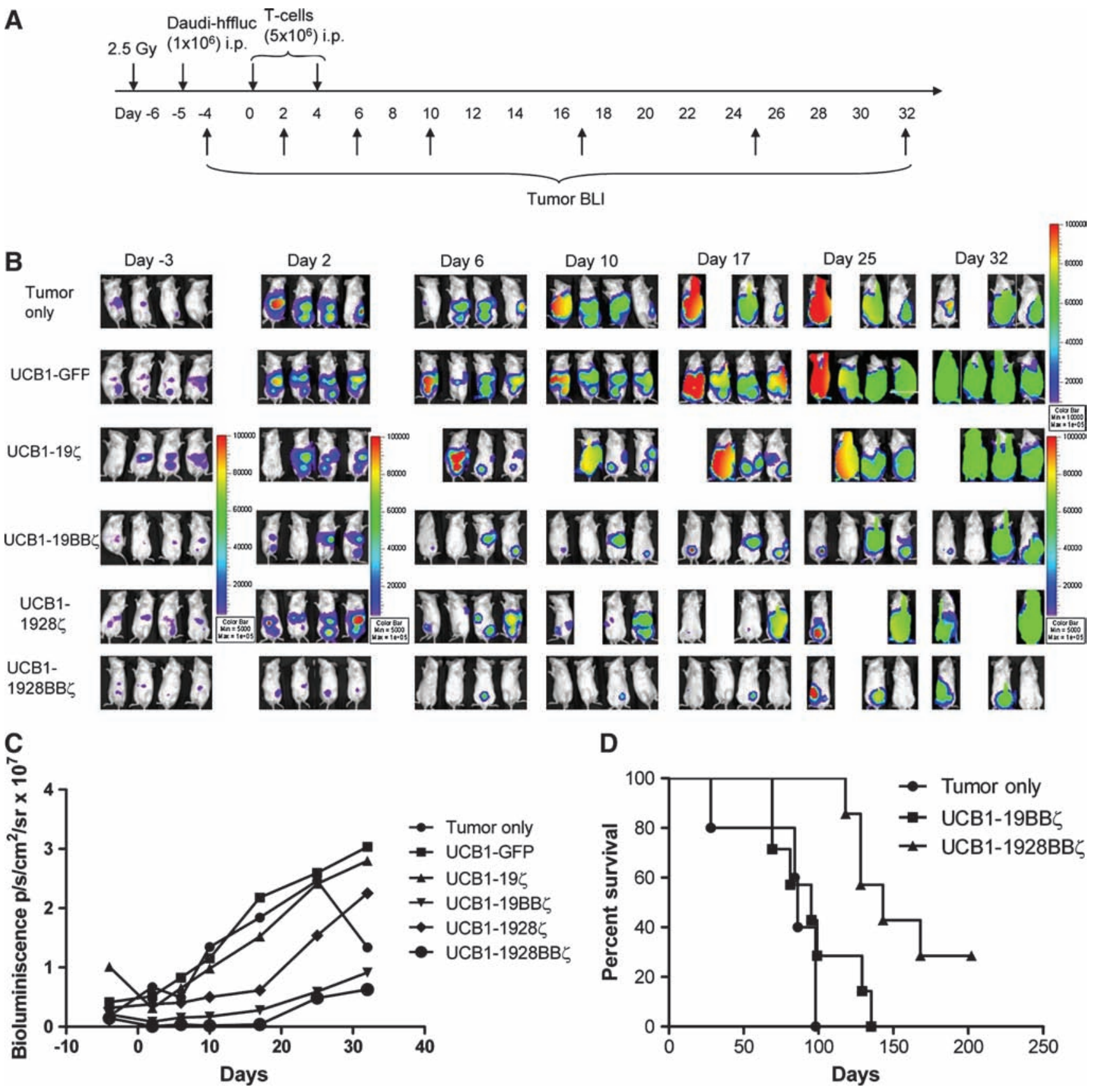

FIG. 5. In vivo antitumor responses by the engineered T cells in a local tumor model. (A) The experimental schedule. (B) BLI of tumor growth in NOD/SCID mice (six groups, $n=4$ each) treated with the engineered UCB1 T cells expressing $19 \zeta, 19 \mathrm{BB} \zeta$, $1928 \zeta, 1928 \mathrm{BB} \zeta$, and GFP. One mouse each in UCB-19 $\zeta$ (day 6) and UCB-1928 $\zeta$ (day 10) groups died because of the anesthetic procedure for imaging. (C) Bioluminescent intensity of the mice treated with the engineered UCB. Establishment of luciferaseexpressing CD19 ${ }^{+}$Daudi cells was described previously (Huang et al., 2008). (D) Animal survival after T-cell therapy (three groups, $n=5-7$ each). BLI, bioluminescent imaging.

malignancies have high levels of CD19 expression, the low expression of $1928 \zeta$ and $1928 \mathrm{BB} \zeta$ CARs should compensate to render complete activation and effector functions of the $\mathrm{T}$ cells (Weijtens et al., 2000). As is the case with murine T cells, whether removal of this dileucine motif would lead to enhanced 28 and 28BB CAR expression and subsequent functions in UCB $\mathrm{T}$ cells remains to be examined.

We observed superior activity of CD19 CAR containing 41BB signaling alone (UCB-19BB $\zeta$ ) or both CD28 and 4-1BB signaling domains (UCB-1928BB $\zeta$ ) compared with the same CAR with CD28 signaling alone (UCB-1928) ) or without signaling domain (UCB-19 $\zeta$ ) in in vitro cytotoxicity against B-cell lymphoma Daudi cells (Fig. 3A and B). Our findings are also in agreement with published reports demonstrating that integration of 4-1BB signaling in CARs enhances PBL-derived T-cell cytotoxicity (Imai et al., 2004; Marin et al., 2007; Milone et al., 2009). However, we did not observe a differential effect of CD28 or $4-1 \mathrm{BB}$ signaling or both on IFN- $\gamma$ and IL-2 pro- 
A

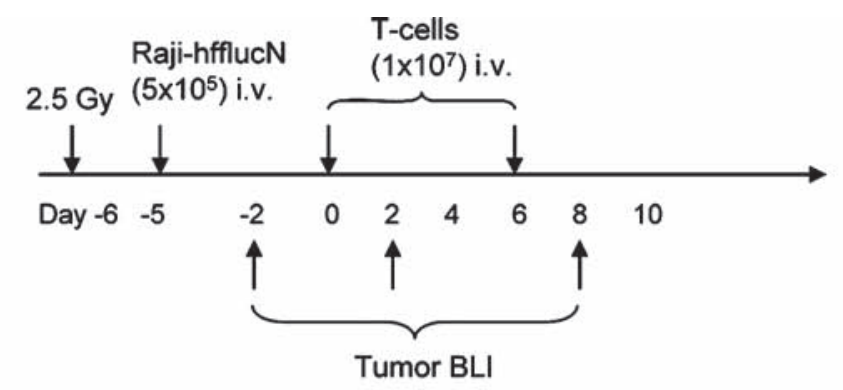

B

Day -2

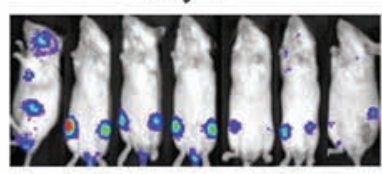

Day 2
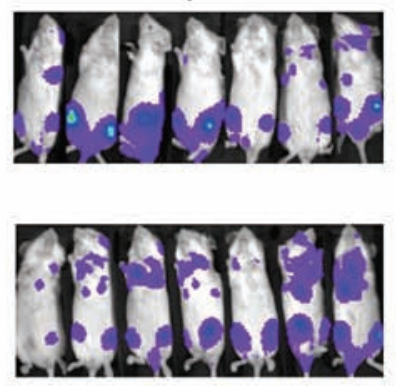

$-\infty \infty$
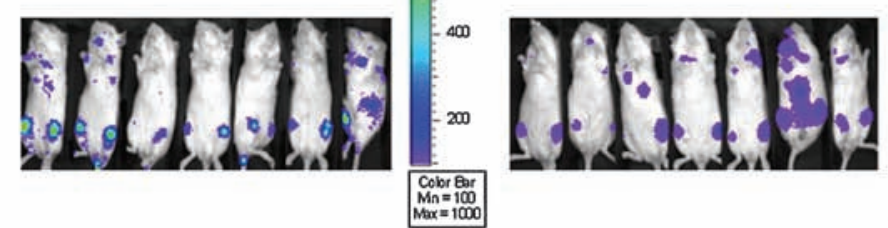
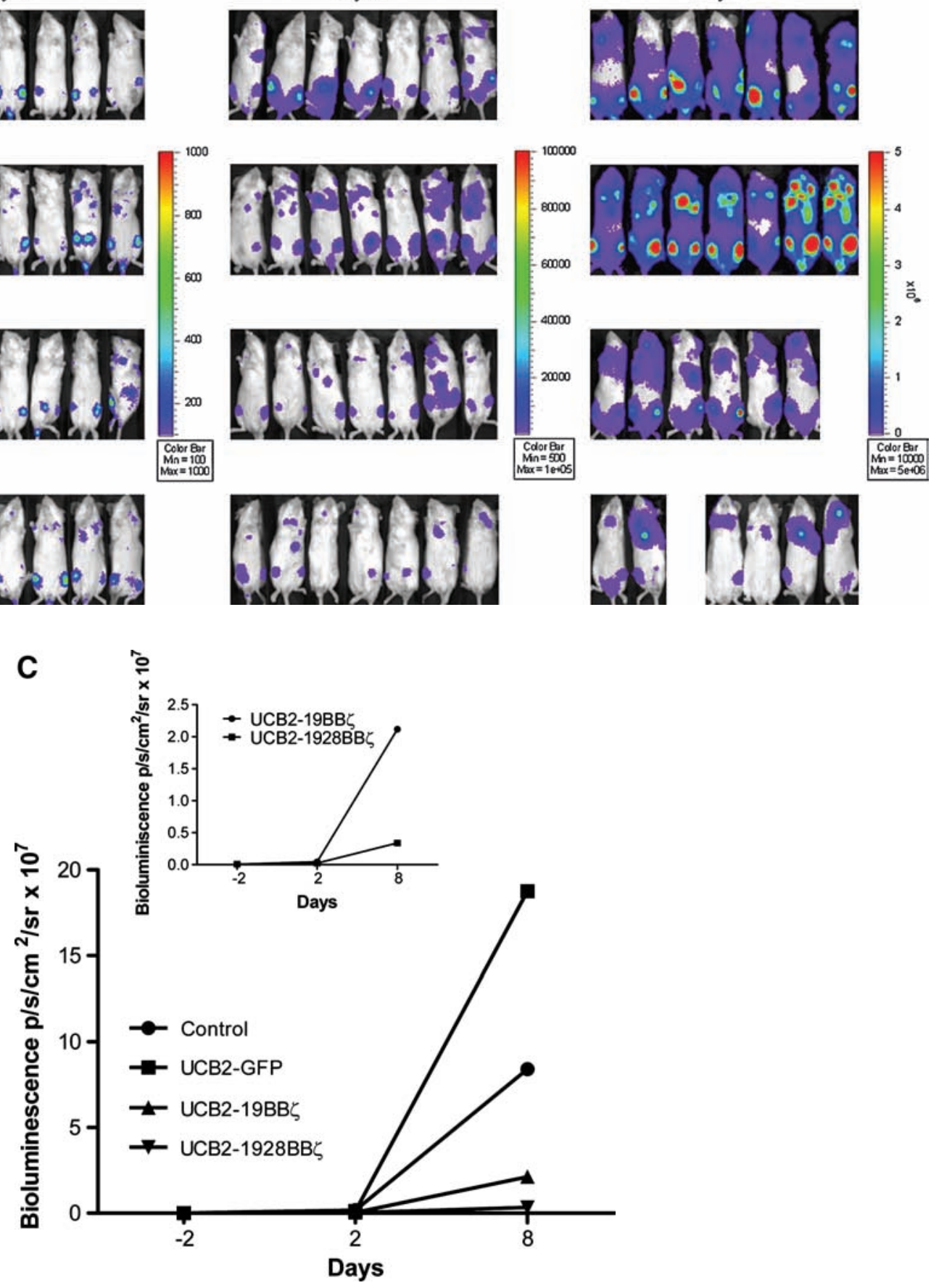

FIG. 6. In vivo antitumor responses by the engineered $\mathrm{T}$ cells in a systemic mouse model. (A) The experimental schedule. (B) BLI of tumor growth in NOD/SCID mice (four groups, $n=7$ each) treated with the engineered UCB2 T cells expressing $19 \mathrm{BB} \zeta, 1928 \mathrm{BB} \zeta$, and GFP. Raji cells were transduced with a lentiviral vector expressing humanized firefly luciferase and truncated NGFR (hffluc/ $\triangle$ NGFR) and subsequently sorted for NGFR expression. (C) Bioluminescent intensity of the mice treated with the engineered UCB2 T cells. NGFR, nerve growth factor receptor. 
duction in response to CD19 antigen stimulation (Fig. 4A and B). The discrepancy between our data in this report (supported by Marin et al., 2007; Milone et al., 2009) and other reports (Finney et al., 1998, 2004; Krause et al., 1998; Maher et al., 2002; Haynes et al., 2002a,b; Imai et al., 2004; FriedmannMorvinski et al., 2005; Kowolik et al., 2006; Serrano et al., 2006; Brentjens et al., 2007; Wang et al., 2007) can be explained by two possible reasons. First, the source of $\mathrm{T}$ cells that we studied is derived from UCB, whereas others used PBLs. It is evident that the majority of UCB T cells bear a naive phenotype, whereas PBLs contain both naive and memory $\mathrm{T}$ cells (Hassan and Reen, 1997; Barker and Wagner, 2003; Kaminski et al., 2003; Chao et al., 2004; Kloosterboer et al., 2006). Thus, the optimal costimulation requirement for UCB and PBL is likely to be different. Our observation is supported by recent publications showing that CD28 costimulation is essential for PBL- but not UCB-derived human regulatory T-cell expansion and function, whereas $4-1 \mathrm{BB}$ or OX40 is required for UCBderived regulatory T-cell expansion and function (Golovina et al., 2008; Hippen et al., 2008). Second, the nature of the antigen used for stimulation in this study is $\mathrm{CD} 19^{+}$tumor cells or CD19 transfectants. In contrast, others have used artificially plate-bound soluble antigens, which may not provide a full engagement with CAR and also exclude cell adhesion and molecule-mediated cell-cell interaction (Finney et al., 1998; Finney et al., 2004; Imai et al., 2004).

Nevertheless, we did observe a different effect of engineered UCB T cells with 4-1BB signaling alone or both 4$1 \mathrm{BB}$ and $\mathrm{CD} 28$ in the in vitro cytotoxicity and in vivo adoptive transfer experiments. We also demonstrated a superior synergistic effect mediated by both $4-1 \mathrm{BB}$ and CD28 signaling but not by CD28 or $4-1 \mathrm{BB}$ alone in antitumor responses in both local and systemic tumor models (Figs. 5C, D, and 6C). Engineered UCB T cells with $4-1 \mathrm{BB}$ and CD28 were able to home to the tumor sites and mediate tumor regression (Fig. 6C). The mechanism behind the superior antitumor effect by CAR with 4-1BB and CD28 cosignaling is not presently clear. We speculate that both 4-1BB and CD28 signaling via CAR engagement with CD19 on tumor cells enhance T-cell survival, persistence, and cytotoxicity in the tumor microenvironment as it has been documented that 4-1BB and CD28 signaling upregulate $\mathrm{Bcl}-2$ and $\mathrm{Bcl}-\mathrm{xL}$ expression (Finney et al., 2004; Watts, 2005; Kowolik et al., 2006; Carpenito et al., 2009). 4-1BB costimulation also restores downregulated NKG2D expression in UCB CD8 $\mathrm{T}$ cells after ligation of NKG2D, leading to enhanced NKG2D-mediated tumor killing (Kim et al., 2008; Zhang et al., 2007). Importantly, the cytotoxic activity and NKG2D induced by 4$1 \mathrm{BB}$ are refractory to transforming growth factor (TGF)- $\beta 1$ downmodulation, because TGF- $\beta$ is one of the immunosuppressive cytokines produced by tumor cells (Kim et al., 2008). More recently, CD28 has been shown to regulate memory T-cell trafficking to target tissue, suggesting that CD28 can have additional functions beyond that of costimulation (Mirenda et al., 2007). Dissecting the mechanisms of the superior effector function of the CAR-engineered UCB T cells by $4-1 B B$ and CD28 signaling awaits further investigation.

In summary, we have demonstrated that 4-1BB signaling is more critical than CD28 in generating CD19 CAR-redirected UCB effector T cells. Further, integration of both 4-1BB and CD28 signaling domains into CD19 CAR can induce the most potent antitumor effector UCB T cells and should be integrated into the development of engineered UCB T-cell therapy for refractory leukemia and lymphoma.

\section{Acknowledgments}

The authors are grateful to Cindy Eide for editing the article and Arlys Clements for secretarial assistance. The authors also thank Drs. Luigi Naldini and Mario Amendola (San Raffaele Telethon Institute for Gene Therapy, Milan, Italy) for providing the bidirectional PGK/mCMV promoter. This work was supported by grants from the Alliance for Cancer Gene Therapy, the Gabrielle's Angel (formerly G\&P) Foundation for Cancer Research, the Sidney Kimmel Foundation for Cancer Research Kimmel Scholar Program, the University of Minnesota Translational Research Grant, the University Minnesota Medical School Dean's Commitment, Leukemia Research Fund, and in part by the Children's Cancer Research Fund in Minneapolis (to X.Z.).

\section{Contribution Statement}

S.T. designed and performed the research, analyzed the data, and wrote the paper. X.H. and M.W. performed the research and analyzed the data. M.C.M. performed the research. L.M. performed the statistical analyses. B.L.L., C.H.J., J.E.W., and B.R.B. provided critical reagents, discussed the work, and edited the article. X.Z. designed and performed the research, analyzed the data, and wrote the article.

\section{Author Disclosure Statement}

C.H.J. is an inventor of a reagent (CD3/CD28 beads) used in the manufacturing of lentivirus-engineered $\mathrm{T}$ cells and therefore has the potential to receive royalties from its commercial use.

Others have no competing financial interests.

\section{References}

Altvater, B., Pscherer, S., Landmeier, S., Niggemeier, V., Juergens, H., Vormoor, J., and Rossig, C. (2006). CD28 co-stimulation via tumor-specific chimeric receptors induces an incomplete activation response in Epstein-Barr virus-specific effector memory T cells. Clin. Exp. Immunol. 144, 447-457.

Amendola, M., Venneri, M.A., Biffi, A., Vigna, E., and Naldini, L. (2005). Coordinate dual-gene transgensis by lentiviral vectors carrying synthetic bidirectional promoters. Nat. Biotechnol. 23, 108-116.

Barker, J.N., and Wagner, J.E. (2003). Umbilical-cord blood transplantation for the treatment of cancer. Nat. Rev. Cancer 3, 526-532.

Brentjens, R.J., Latouche, J.B., Santos, E., Marti, F., Gong, M.C., Lyddane, C., King, P.D., Larson, S., Weiss, M., Rivière, I., and Sadelain, M. (2003). Eradication of systemic B-cell tumors by genetically targeted human $\mathrm{T}$ lymphocytes co-stimulated by CD80 and interleukein-15. Nat. Med. 9, 279-286.

Brentjens, R.J., Santos, E., Nikhamin, Y., Yeh, R., Matsushita, M., La Perle, K., Quintàs-Cardama, A., Larson, S.M., and Sadelain, M. (2007). Genetically targeted T cells eradicate systemic acute lymphoblastic leukemia xenografts. Clin. Cancer Res. 13, 5426-5435.

Carpenito, C., Milone, M.C., Hassan, R., Simonet, J.C., Lakhal, M., Suhoski, M.M., Varela-Rohena, A., Haines, K.M., Heitjan, D.F., Albelda, S.M., Carrol, R.G., Riley, J.L., Pastna, I., and June, C.H. (2009). Control of large, established tumor xeno- 
grafts with genetically retargeted human $\mathrm{T}$ cells containing CD28 and CD137 domains. Proc. Natl. Acad. Sci. U. S. A. 3, 3360-3365.

Chao, N., Emerson, S.G., and Weinberg, K.I. (2004). Stem cell transplantation (cord blood transplants). Hematol. Am. Soc. Hematol. Educ. Program 2004, 354-363.

Cooper, L.J.N., Topp, M.S., Serrano, L.M., Gonzalez, S., Chang, W.C., Naranjo, A., Wright, C., Popplewell, L., Raubitschek, A., Forman, S.J., and Jensen, M.C. (2003). T-cell clones can be rendered specific for CD19: toward the selective augmentation of the graft-versus-B-lineage leukemia effect. Blood 101, 1637-1644.

Eshhar, Z., Waks, T., Gross, G., and Schindler, D.G. (1993). Specific activation and targeting of cytotoxic lymphocytes through chimeric single chains consisting of antibody-binding domains and the gamma or zeta subunits of the immunoglobulin and T-cell receptors. Proc. Natl. Acad. Sci. U. S. A. 90, 720-724.

Finney, H.M., Akbar, A.N., and Lawson, A.D. (2004). Activation of resting human primary $\mathrm{T}$ cells with chimeric receptors: Costimulation from CD28, inducible costimulator, CD134, and CD137 in series with signals from the TCR zeta chain. J. Immunol. 172, 104-113.

Finney, H.M., Lawson, A.D.G., Bebbington, C.R., and Weir, A.N.C. (1998). Chimeric receptors providing both primary and costimulatory signaling in T cells from a single gene product. J. Immunol. 161, 2791-2797.

Friedmann-Morvinski, D., Bendavid, A., Waks, T., Schindler, D., and Eshhar, Z. (2005). Redirected primary T cells harboring a chimeric receptor require costimulation for their antigenspecific activation. Blood 105, 3087-3093.

Golovina, T.N., Mikheeva, T., Suhoski, M.M., Aqui, N.A., Tai, V.C., Shan, X., Liu, R., Balcarcel, R.R., Fisher, N., Levine, B.L., Carroll, R.G., Warner, N., Blazar, B.R., June, C.H., and Riley, J.L. (2008). CD28 costimulation is essential for human T regulatory expansion and function. J. Immunol. 181, 2855-2868.

Greenberg, P.D., and Riddell, S.R. (1999). Deficient cellular immunity-finding and fixing the defects. Science 285, 546-551.

Hassan, J., and Reen, D.J. (1997). Cord blood CD4+ CD45RA+ T cells achieve a lower magnitude of activation when compared with their adult counterparts. Immunology 90, 397-401.

Haynes, N.M., Trapani, J.A., Teng, M.W., Jackson, J.T., Cerruti, L., Jane, S.M., Kershaw, M.H., Smyth., M.J., and Darcy, P.K. (2002a). Rejection of syngeneic colon carcinoma by CTLs expressing single-chain antibody receptors codelivering CD28 costimulation. J. Immunol. 169, 5780-5786.

Haynes, N.M., Trapani, J.A., Teng, M.W., Jackson, J.T., Cerruti, L., Jane, S.M., Kershaw, M.H., Smyth, M.J., and Darcy, P.K. (2002b). Single-chain antigen recognition receptors that costimulate potent rejection of established experimental tumors. Blood 100, 3155-3163.

Hippen, K.L., Harker-Murray, P., Porter, S.B., Merkel, S.B., Londer, A., Taylor, D.K., Bina, M., Panoskaltsis-Mortari, A., Rubinstein, P., Van Rooijen, N., Golovina, T.N., Suhoski, M.M., Miller, J.S., Wagner, J.E., June, C.H., Riley, J.L., and Blazar, B.R. (2008). Umbilical cord blood regulatory T-cell expansion and functional effects of tumor necrosis factor receptor family members OX40 and 4-1BB expressed on artificial antigen-presenting cells. Blood 112, 2847-2857.

Huang, X., Guo, H., Kang, J., Choi, S., Zhou, T.C., Tammana, S., Lees, C.J., Li, Z.Z., Milone, M., Levine, B.L., Tolar, J., June, C.H., McIvor, S., Wagner, J.E., Blazar, B.R., and Zhou, X. (2008). Sleeping beauty transposon-mediated engineering of human primary $\mathrm{T}$ cells for therapy of CD19+ lymphoid malignancies. Mol. Ther. 16, 580-589.
Imai, C., Mihara, K., Andreansky, M., Nicholson, I.C., Pui, C.H., Geiger, T.L., and Campana, D. (2004). Chimeric receptors with $4-1 \mathrm{BB}$ signaling capacity provoke potent cytotoxicity against acute lymphoblastic leukemia. Leukemia 18, 676-684.

Kaminski, B.A., Kadereit, S., Miller, R.E., Keahy, P., Stein, K.R., Topa, D.A., Radivoyevitch, T., Veigl, M.L., and Laughlin, M.J. (2003). Reduced expression of NFAT-associated genes in UCB versus adult $\mathrm{CD} 4+\mathrm{T}$ lymphocytes during primary stimulation. Blood 102, 4608-4617.

Kim, Y.-J., Han, M.-K., and Broxmeyer, H.E. (2008). 4-1BB regulates NKG2D costimulation in human cord blood CD8+ T cells. Blood 111, 1378-1386.

Kloosterboer, F.M., Van Luxemburg-Heijs, S.A., Willemze, R., and Falkenburg, J.H. (2006). Similar potential to become activated and proliferate but differential kinetics and profiles of cytokine production of umbilical cord blood T cells and adult blood naive and memory T cells. Hum. Immunol. 67, 874-883.

Kowolik, C.M., Topp, M.S., Gonzalez, S., Pfeiffer, T., Olivares, S., Gonzalez, N., Smith, D.D., Forman, S.J., Jensen, M.C., and Cooper, L.J. (2006). CD28 costimulation provided through a CD19-specific chimeric antigen receptor enhances in vivo persistence and antitumor efficacy of adoptively transferred $\mathrm{T}$ cells. Cancer Res. 66, 10995-11004.

Krause, A., Guo, H.F., Latouche, J.B., Tan, C., Cheung, N.K., and Sadelain, M. (1998). Antigen-dependent CD28 signaling selectively enhances survival and proliferation in genetically modified activated human primary lymphocytes. J. Exp. Med. 188, 619-626.

Loskog, A., Giandomenico, V., Rossig, C., Pule, M., Dotti, G., and Brenner, M.K. (2006). Addition of the CD28 signaling domain to chimeric T-cell receptors enhances chimeric T-cell resistance to T regulatory cells. Leukemia 20, 1819-1828.

Maher, J., Brentjens, R.J., Gunset, G., Riviere, I., and Sadelain, M. (2002). Human T-lymphocyte cytotoxicity and proliferation directed by a single chimeric TCR $\zeta / C D 28$ receptor. Nat. Biotechnol. 20, 70-75.

Marin, V., Kakuda, H., Dander, E., Imai, C., Campana, D., Biondi, A., and D'Amico, G. (2007). Enhancement of the antileukemic activity of cytokine induced killer cells with an antiCD19 chimeric receptor delivering a 4-1BB- $\zeta$ activating signal. Exp. Hematol. 35, 1388-1397.

Milone, M.C., Fish, J.D., Carpenito, C., Carroll, R.G., Binder, G.K., Teachey, D., Samanta, M., Lakhal, M., Gloss, B., DanetDesnoyers, G., Campana, D., Riley, J.L., Grupp, S.A., and June, C.H. (2009). Chimeric receptors containing CD137 signal transduction domains mediate enhanced survival of $\mathrm{T}$ cells and increased antileukemic efficacy in vivo. Mol. Ther. 17, 1453-1464.

Mirenda, V., Jarmin, S.J., David, R., Dyson, J., Scott, D., Gu, Y., Lechler, R.I., Okkenhaug, K., and Marelli-Berg, F.M. (2007). Physiologic and aberrant regulation of memory T-cell trafficking by the costimulatory molecule CD28. Blood 109, 2968-2977.

Nguyen, P., Moisini, I., and Geiger, T.L. (2003). Identification of a murine CD28 dileucine motif that suppresses single-chain chimeric T-cell receptor expression and function. Blood 102, 4320-4325.

Pule, M.A., Straathof, K.C., Dotti, G., Heslop, H.E., Rooney, C.M., and Brenner, M.K. (2005). A chimeric T cell antigen receptor that augments cytokine release and support clonal expansion of primary human T cells. Mol. Ther. 12, 933-941.

Riddell, S.R., and Greenberg, P.D. (1990). The use of anti-CD3 and anti-CD28 monoclonal antibodies to clones and expand human antigen-specific T cells. J. Immunol. Methods 128, 189-201.

Risdon, G., Gaddy, J., Horie, M., and Broxmeyer, H.E. (1995). Alloantigen priming induces a state of unresponsiveness in 
human umbilical cord blood T cells. Proc. Natl. Acad. Sci. U. S. A. 92, 2413-2417.

Rosenberg, S.A., Restifo, N.P., Yang, J.C., Morgan, R.A., and Dudley, M.K. (2008). Adoptive cell transfer: A clinical path to effective cancer immunotherapy. Nat. Rev. Cancer 8, 299-308.

Rossig, C., and Brenner, M. (2004). Genetic modification of T lymphcytes for adoptive immunotherapy. Mol. Ther. 10, 5-18.

Sadelain, M., Riviere, I., and Brentjens, R. (2003). Targeting tumours with genetically enhanced $\mathrm{T}$ lymphocytes. Nat. Rev. Cancer 3, 35-45.

Sallusto, F., and Lanzavecchia, A. (2004). Central memory and effector memory $\mathrm{T}$ cell subsets: Function, generation, and maintenance. Ann. Rev. Immunol. 22, 745-763.

Serrano, L.M., Pfeiffer, T., Olivares, S., Numbenjapon, T., Bennitt, J., Kim, D., Smith, D., McNamara, G., Al-Kadhimi, Z., Rosenthal, J., Forman, S.J., Jensen, M.C., and Cooper, L.J. (2006). Differentiation of naive cord-blood T cells into CD19specific cytolytic effectors for post transplantation adoptive immunotherapy. Blood 107, 2643-2652.

Wang, J., Jensen, M., Lin, Y., Sui, X., Chen, E., Lindgren, C.G., Till, B., Raubitschek, A., Forman, S.J., Qian, X., James, S., Greenberg, P., and Press, O.W. (2007). Optimizing adoptive polyclonal $\mathrm{T}$ cell immunotherapy of lymphomas, using a chimeric T cell receptor processing CD28 and CD137 costimulatory domains. Hum. Gene Ther. 18, 712-725.
Watts, T.H. (2005). TNF/TNFR family members in costimulation of T cell responses. Ann. Rev. Immunol. 23, 23-68.

Weijtens, M.E., Hart, E.H., and Bolhuis, R.L. (2000). Functional balance between $\mathrm{T}$ cell chimeric receptor density and tumor associated antigen density: CTL mediated cytolysis and lymphokine production. Gene Ther. 7, 35-42.

Zhang, H., Snyder, K.M., Suhoski, M.M., Maus, M.V., Kapoor, V., June, C.H., and Mackall, C.L. (2007). 4-1BB is superior to CD28 costimulation for generating CD8+ cytotoxic lymphocytes for adoptive immunotherapy. J. Immunol. 179, 49104918.

Address correspondence to: Xianzheng Zhou, M.D., Ph.D. University of Minnesota Masonic Cancer Center MMC 366, 420 Delaware St. Minneapolis, MN 55455

E-mail: zhoux058@umn.edu.

Received for publication July 14, 2009; accepted after revision August 31, 2009.

Published online: December 17, 2009. 